\title{
Can we Measure Mesopic Pupil Size with the Cobalt Blue Light Slit-lamp
}

\section{Biomicroscopy Method?}

Miguel J. Maldonado, MD, PhD; ${ }^{1,2}$ Alberto López-Miguel, MSc; ${ }^{1,2}$ David P. Piñero, $\mathrm{PhD} ;{ }^{3}$ José R. Juberías, MD, PhD ${ }^{1,2}$ Juan C Nieto, MSc, ${ }^{4}$ Jorge L Alió, MD, PhD ${ }^{5}$

${ }^{1}$ From IOBA, Institute of Applied Ophthalmobiology, University of Valladolid, Valladolid, Spain.

${ }^{2}$ From Clínica Universidad de Navarra, Departamento de Oftalmología, Pamplona, Spain

${ }^{3}$ From Departamento de Óptica, Farmacología y Anatomía, University of Alicante, Alicante, Spain.

${ }^{4}$ From Optometry and Vision Sciences Unit, Optics Department, University of Valencia, Valencia, Spain.

${ }^{5}$ From Vissum/Instituto Oftalmológico de Alicante, Alicante, Spain.

The authors have no financial interest in any aspect of this study.

The authors have full control of all primary data and they agree to allow Graefes Archive for Clinical and Experimental Ophthalmology to review their data upon request.

Corresponding author: Miguel J. Maldonado, MD, PhD. IOBA. Paseo Belén, 17. 47011 Valladolid. Email: maldonado@ioba.med.uva.es. Tlf: 983184750. 


\section{ABSTRACT}

Background: To assess a previously described slit-lamp biomicroscopy-based method (SLBM) for measuring pupil diameter and compare it with Colvard infrared pupillometry (CIP).

Methods: Two examiners performed three repeated measurements with each instrument in forty healthy eyes. We determined the agreement of SLBM and CIP, intraobserver and interobserver repeatabilities, and interobserver concordance (kappa) and SLBM ability for detecting pupil sizes over $6.0 \mathrm{~mm}$.

Results: The mean ( \pm standard deviation [SD]) pupil diameter was $5.81 \pm 0.70 \mathrm{~mm}$ with SLBM and $6.26 \pm 0.68 \mathrm{~mm}$ with CIP $(\mathrm{p}=0.01)$ averaging both examiner's results. Mean differences between the SLBM and CIP were $-0.60 \mathrm{~mm}$ and $-0.30 \mathrm{~mm}$ for each examiner using the average of the three readings $(\mathrm{p}=0.02)$, and they were very similar using the first reading. Intraobserver reproducibility: the width of the 95\% LoA ranged from 1.79 to $2.30 \mathrm{~mm}$. The ICCs were 0.97 and 0.92 for SLBM, and 0.96 and 0.90 for CIP. Interobserver reproducibility: the width of the LoA ranged from 1.82 to $2.09 \mathrm{~mm}$. Kappa statistics were 0.39 and 0.49 for the first and mean SLBM readings, respectively, and 0.45 for both the first and mean CIP readings. Sensitivity and specificity of SLBM for detection of pupils larger than $6 \mathrm{~mm}$ ranged from $55.56 \%$ to $73.68 \%$ and from $76,19 \%$ to $95,45 \%$, respectively. The best trade-off between sensitivity and specificity ranged from $5.4 \mathrm{~mm}$ to $6.2 \mathrm{~mm}$.

Conclusions: Although the SLBM is quite repeatable, it underestimates mesopic pupil size and shows a too wide range of agreement with CIP. SLBM shows low sensitivity in detecting pupils larger than $6 \mathrm{~mm}$, which may be misleading when planning anterior segment surgery. Therefore, SLBM measurements appear not to be accurate enough clinically to make valid calculations and to reach appropriate surgical decisions. 


\section{KEYWORDS}

Pupillometry, slit-lamp biomicroscopy-based method; Colvard infrared pupillometer. 


\section{INTRODUCTION}

Pupil diameter can be a limiting factor to a perfect outcome after intraocular lens (IOL) implantation, particularly of multifocal pseudophakic and monofocal phakic IOLs, and keratorefractive surgery because it may affect visual performance and patient satisfaction [1-7]. On one hand, pupil diameter under different lighting conditions should be measured and coupled with the optics of the multifocal IOL to meet patients' needs. Otherwise dissatisfaction should be expected in the presbyopic patient [6]. On the other hand, patients with pupils enlarging well over the maximum 6-mm optic diameter of a phakic IOL are likely to complain of disabling halo and night vision disturbances [5]. Last, although it is a matter of controversy, for an optimal keratorefractive procedure, excimer laser effective optical zones should be larger than the entrance pupil diameter to preclude foveal and parafoveal glare [ 0 for all the above mentioned reasons, pupillometry, at least under low mesopic (LM) conditions, should be desirably performed before patient counseling and surgery planning.

Various methods have been used for determining pupil size: comparison methods, videokeratography, several infrared methods and digital photography among others. [818]. Additionally, Starck et al [19]. have described a slit-lamp biomicroscopy-based method (SLBM) for measuring pupil size. We hypothesized that if this method of pupil measurement were comparable to traditional infrared pupillometry, then its use would increase the quality of care of many vision centers in which pupil size might not be appropriately measured due to lack of specific instrumentation. This study aimed therefore to evaluate the performance of SLBM pupillometry under LM illumination and compare it with an infrared pupillometer (Colvard pupillometer, Oasis Medical; Glendora, CA), which is being used commonly in the clinical setting [2,8,10,12,14,15,20-26]. 


\section{MATERIALS AND METHODS}

The principles outlined in the Declaration of Helsinki were followed during this study. All candidates received detailed information about the nature of the investigation, and all provided informed consent. This project was approved by the local Institutional Review Board.

This prospective study was conducted at Clínica Universidad de Navarra, University of Navarra, Navarra, Spain, during June and July 2009. Pupil diameter under LM conditions was measured in 40 healthy eyes of 20 refractive surgery candidates without strabismus ( 5 men and 15 women) ranging in age from 22 to 54 years old (mean \pm standard deviation (SD), $34.5 \pm 7.4$ years). None of them were under systemic or ocular medications. Mean sphere determined by subjective refraction was $-2.93 \pm 3.10$ diopters (D) (range +5.00 to $-9.00 \mathrm{D}$ ), and mean cylinder was $-0.84 \pm 0.85 \mathrm{D}$ (range 0.00 to -3.25 D). Pupillometry was performed three times by two independent similarly experienced examiners: the same slit-lamp-based cobalt blue light and the same infrared pupillometer.

Measurements were taken after 5 minutes of dark adaptation with a period of 15 seconds of darkness between each measurement and less than 30 seconds between observers. The lighting conditions of the examining room were not altered throughout the whole measurement process of each individual. Subjects were reminded to fixate on a distant (6 meters) target during measurements to avoid accommodation, and were asked to inform examiners if the view was obstructed. We measured with a light meter (Light ProbeMeter $^{\mathrm{TM}}$, Extech Instruments, Waltham, MA) that the illuminance produced with this method in the examination room ranged from 0.5 to 0.7 lux at eye height. Under this lighting condition, pupil diameter can be easily determined and might reproduce the level of light typically encountered while driving on a suburban street at night $[10,26]$. The examiners attempted to measure the largest pupil in the hippus cycle for both techniques 
and were masked to each other's measurements. In order to reduce examiner or method dependent-related bias, the measurements were taken following the diagram shown in figure 1.

When Colvard infrared pupillometry (CIP) was performed, the subject was instructed to focus on a target placed at 6 meters with the fellow eye, a millimeter ruler was superimposed by a reticule in the device, which allowed direct measurement of the pupil diameter due to light amplification technology [2]. We assured that the pupil always lined up with the reticule. The CIP can measure the vertical and horizontal pupils to $0.5 \mathrm{~mm}$ increments, and analysis was performed rounding to the nearest $0.5 \mathrm{~mm}$.

Pupillometry with the SLBM was performed as described by Starck and coworkers [19]. The background illuminance conditions of the examination room were the same as with the CIP. After sitting the patient in front of the biomicroscope, the cobalt blue filter was selected, the light intensity knob on the cross-slide base was rotated to the lowest position and the slit narrowed in order to reduce brightness to the minimum. This way, we measured a mean focal illumination of 6 lux for an average 6.5 mm-long slit in our set-up. The slit was set in the vertical position, the image of the iris was then perfectly focused, and by rotating the knob, the length of the light beam was adjusted according to the pupil diameter. Therefore, the number indicated in the slit length display window was the measurement of the pupil size. With this procedure the pupil size was measured to $0.1-\mathrm{mm}$ increments.

We ensured proper calibration of both instruments by measuring machinistdrilled holes with precise diameters in a paper sheet and both devices showed no instrument bias.

Data were entered onto a computerized database, and statistical calculations were performed using a commercially available statistical package (SPSS version 15.0 
for Windows). In order to detect any significant systematic bias, the results obtained for each method and for each examiner were compared with analysis of variance with subsampling, which is an appropriate statistical test for two-eye designs [27]. Statistical analysis of the agreement between the two techniques was performed with the method described by Bland and Altman [28]. The 95\% limits of agreement (LoA) were defined as the mean difference in measurements using the two techniques \pm 1.96 SD [28]. Agreement analysis was performed using both, the first measurement and the mean of the three measurements. Although taking three measurements might not be common clinical practice, we wanted to investigate whether this method might improve the repeatability compared with taking single measurements. The corrected SD of differences for the three repeated measurements was calculated with the following formula [28].

$$
S=\sqrt{s_{D}^{2}+\frac{1}{9} s_{1}^{2}+\frac{1}{9} s_{2}^{2}+\frac{1}{9} s_{3}^{2}}
$$

where $s_{1}, s_{2}$ and $s_{3}$ are the SD of the differences of the first, second and third measurement, respectively, and $s_{D}$ is the SD of the differences between the means for each method. We calculated also the width of the LoA that could be attributable to the different measurement precision of both devices.

To evaluate the intraobserver repeatability we calculated the within-subject standard deviation $\left(\mathrm{S}_{\mathrm{w}}\right)$, the within-subject coefficient of variation $\left(\mathrm{CV}_{\mathrm{w}}\right)$, and the intraclass correlation coefficient (ICC) of the three consecutive pupil size measurements [29]. The interobserver reproducibility of both methods was assessed using the Bland and Altman plot [28]. The coefficients of interobserver reproducibility for each pupillometry technique were 1.96 times the SD of the differences between both examiners' measurements, lower values indicating higher reproducibility [28]. The 
simple $\kappa$ statistics and $95 \%$ confidence intervals (CI) were used to examine the interobserver reliability in detecting pupils over $6 \mathrm{~mm}$ in diameter [30]. The nomenclature proposed by Fleiss describes kappa levels greater than 0.75 as excellent agreement, between 0.4 and 0.74 as fair to good, and below 0.4 as poor [30].

Sensitivity and specificity calculations of the SLBM for detection of 6-mm pupil sizes were performed. We selected a $6 \mathrm{~mm}$ pupil diameter cut off because it is typically the maximum optic diameter of the phakic and pseudophakic IOLs [5,31], and as a result of reviewing several studies where Colvard had been used for measuring pupil size under LM illumination $[10,12,16,17,21,24,33,34]$. The mean pupillometry reported in these studies was $5.98+/-0.19 \mathrm{~mm}$. Colvard measurements were used as the reference standard for calculations of sensitivity and specificity. Additionally, we calculated the overall efficiency (proportion of correct results) of the SLBM.

Finally, the ability of the SLBM procedure to discriminate 6-mm pupil diameters was also investigated with receiver operating characteristic (ROC) curves [35]. The best cutpoint for balancing the sensitivity and specificity of the test is the one represented by the point on the curve closest to the upper left-hand corner $[35,36]$. The area under the ROC curve (AUC) was also calculated [35,36], which represented the aggregate goodness of the test in separating eyes with pupils over $6 \mathrm{~mm}$ in diameter from those of $6 \mathrm{~mm}$ or less. For all statistical tests, a two-tailed $\mathrm{p}<0.05$ was considered significant.

\section{RESULTS}

\section{Pupil diameter}

Table 1 provides the average values of the pupil measurements determined by each examiner for each method. The mean pupil diameter was smaller with the SLBM than with the CIP (mean difference $=-0.45 \mathrm{~mm} ; \mathrm{p}=0.01$ ). Overall, both examiners obtained similar values with the infrared pupillometry (mean difference $=0.02 \mathrm{~mm} ; \mathrm{p}=0.81$ ). However, 
for the SLBM there was a slight but statistically significant difference among both examiners measurements (mean difference $=-0.28 \mathrm{~mm} ; \mathrm{p}=0.02$ ).

\section{$\underline{\text { Agreement between techniques }}$}

Table 2 shows the 95\% LoA between slit-lamp and infrared pupillometry. Using both, the first measurement and the mean of the three measurements, the results were very similar. Figure 2 depicts that in all the scatterplots at least $95 \%$ of the points were within the area of mean $\pm 1.96 \mathrm{SD}$, and no definite relationship between the measurement error and the average measurement was shown. The LoA were wide, clinically relevant, and slightly larger when the mean of the three repeated measurements was considered (Table 2). The mean difference between techniques was statistically significant and among pupillometry techniques for examiner 1 was twice the value obtained by examiner 2.

$\underline{\text { Intraobserver repeatability }}$

Table 3 shows that the $S_{\mathrm{w}}$ and $\mathrm{CV}_{\mathrm{w}}$ behave quite similarly; the SLBM showed marginally better indices than the CIP, and examiner 1 performed generally better than examiner 2. The same is indicated by the ICCs, which showed overall good intraobserver repeatability.

Interobserver reproducibility

Table 4 shows the LoA between examiner 1 and examiner 2 for each pupillometry technique. For the first measurement the range of mean differences among the examiners was similar for both pupillometry techniques, but it appeared to be smaller with the infrared pupillometry when we used the mean of the three repeated readings. Mean difference between examiners for the SLBM pupillometry was small but statistically significant, whereas it was not significant for the CIP. 
Figure 3 shows the interobserver differences plotted against the mean measurements using the CIP and the SLBM. Examiner 1 tended to underestimate the medium-sized pupils with the SLBM. Table 5 lists the coefficients of interobserver reproducibility for each pupillometry technique and for each analysis (first measurement or average). The values obtained were near $1 \mathrm{~mm}$ and they were similar for the first measurement. With the mean of the three repeated measurements, the repeatability of the infrared pupillometry was slightly better than that of the slit-lamp method. The simple $\kappa$ statistic associated with the interobserver reliability for these data is shown in table 6 . Concordance between observers was shown to be slightly better, even so just fair, for the Colvard than for the slit-lamp method using the first measurement. Only in slit-lamp pupillometry did interobserver reliability improve modestly when the average of three measurements was taken.

Sensitivity and specificity

For the first measurement and for the mean of the three repeated measurements, examiner 1 achieved a lower sensitivity than examiner 2 , but a higher specificity, because of the tendency of examiner 1 to underestimate the pupil diameter with the slit-lamp (table 7). In contrast, examiner 2 achieved a lower efficiency. With the mean of the three repeated measurements the results were better for examiner 1 , but similar for the second examiner.

\section{$\underline{\text { ROC curves }}$}

Table 8 shows the AUCs for each examiner and for each analysis (first measurement and average). For the detection of large pupil sizes the use of mean of the three repeated measurements obtained with the slit-lamp pupillometry for examiner 1 had the largest AUC (figure 4), although the values of the AUCs were very similar in all cases. For a cutoff point on each curve of more than $5.5 \mathrm{~mm}$ or $5.4 \mathrm{~mm}$ (first or mean 
measurements, respectively) for examiner 1, and $6.2 \mathrm{~mm}$ (first and mean measurements) for examiner 2, of pupil diameter we obtained the best trade off between sensitivity and specificity.

\section{DISCUSSION}

Pupillometry with a standard slit-lamp method is appealing because of its simplicity and wide availability. However, the reliability of this measurement method must be properly assessed before it can be applied universally.

Several other studies have measured pupil diameter under mesopic light conditions with different devices. Colvard infrared pupillometry has yielded average pupil diameters ranging from 5.78 to $6.3 \mathrm{~mm}$ in different study populations [10,12,16,17,21,24,33,34]. All these results are comparable to the mean pupil diameter obtained in our study with the CIP $(6.26 \mathrm{~mm})$. In turn, our average values are larger than those found with different devices, the IOWA (Henry Louis, Inc.) infrared pupillometer [9]. and the Rosenbaum card [8]; although other authors stated later just the opposite outcomes when they compared the IOWA pupillometer and the Rosenbaum card with the CIP [16]. These differences among studies might be the result of the diverse illuminance conditions inherent to the measurement method (i.e. provided by the Placido rings), the examination room conditions, the refraction and specially, the average age of the patients analyzed [18]. Because older patients have smaller pupils than younger ones, one should expect lower readings from an older sample of population. Comparison pupillometry using the Rosenbaum card is a technique often used in FDA refractive surgery clinical trials $[2,9,16]$. However, it may be difficult for clinicians to measure with confidence pupil size using the Rosenbaum card in LM conditions using conventional light. Once the illumination is sufficiently low to reflect real-life nocturnal scenarios, it becomes very difficult for the 
examiner to visualize and measure pupil size [2]. Although Ho et al [16]. demonstrated that when using a red light source combined with the Rosenbaum card, the amount of illuminance needed might not be so high compared to CIP, and even, they obtained higher pupil size measurements following the Rosenbaum card method than with CIP.

The results of the current study showed that the systematic bias between SLBM and CIP was significant (between 0.3 and $0.6 \mathrm{~mm}$ ), and the LoA were excessively wide for both examiners. In fact, a range of error from 1.79 to $2.30 \mathrm{~mm}$ is rather considerable, although comparable to the one found by Starck et al [19]. (1.84 to $2.12 \mathrm{~mm}$ ) with SLBM. Specifically, we have shown that the SLBM tended to underestimate the pupil diameter, similarly as Starck et al [19]. found in one of their two observers. This result may be explained by the notably higher illumination with the SLBM, we measured an average of 6 lux, although the brightness and the width of the slit light were reduced to the minimum, while when we performed with CIP, an average magnitude of 0.6 lux was measured. We could not further reduce the intensity of the slit light because it was the lowest level of illumination at which pupil could be measured with confidence. This fact may explain in part the main discrepancy between both methods. Interestingly, with this SLBM, the larger the pupils are, the longer the slit is made to measure the vertical diameter and therefore, the higher illumination of the slit-lamp light source is incident into the eye. There are, however, some other reasons that may have also contributed to the underestimation of the pupil diameter. The spectral sensitivity of the pupillary mechanism has been found to be higher or at least equivalent in the blue part of the spectrum compared to that for other parts of the visible spectrum of equal photopic illuminance $[37,38,39]$. This means that blue light may give rise to smaller pupils compared to those that occur with light of other colors of the same luminance [38]. Additionally, the pupil cycling that originates when the narrow pencil of light is placed at the iris margin, whose contraction is much faster than 
dilation, may have influenced in measuring a smaller pupil in slow dilation motion than pupil is assessed by infrared devices [40]. Beyond that, the close approach of the slit-lamp instrument and examiner to the patient, may have induced intermittently proximal accommodation and convergence that decreased pupil size during the measurement procedure in some cases, despite patients were instructed to constantly fixate at a distant target.

Individual examiners appeared to be internally reliable when obtaining repeated measurements with the same pupillometry technique on multiple occasions, as shown by the $S_{w}$ and $C_{\mathrm{w}}$ as well as the ICC. Our $S_{w}(0.12$ and $0.19 \mathrm{~mm})$ indicated higher intraobserver repeatability than in the study by Starck et al [19]. (0.23 and $0.33 \mathrm{~mm})$ for the same slit-lamp technique. Beyond that, we found similar intraobserver reliability results for each method of measurement. The latter may also denote that the observer's skills were refined enough to obtain consistent measurements with each instrument.

Mean differences between both examiners for the same device rounded zero with the CIP, whereas there was a statistically significant mean difference $(0.3 \mathrm{~mm})$ between each examiner's measurements with the SLBM. This result can be explained by the tendency of examiner 1 to underestimate low-medium-sized pupils with the SLBM (figure 3). The interobserver coefficients of reproducibility showed the presence of differences up to $1.0 \mathrm{~mm}$ (table 5). These coefficients of interobserver reproducibility were better than those of Rosenbaum card comparison $(1.3 \mathrm{~mm})$ [8], similar to those of the VIVA infrared pupillometer (1.1 mm) [10], and worse than the $0.52 \mathrm{~mm}$ value found by Starck et al [19]. for SLBM pupillometry, and others for CIP (from $0.7 \mathrm{~mm}$ to $1.16 \mathrm{~mm}$ ) [8,10,12], Procyon digital pupillometry $(0.64$ and $0.78 \mathrm{~mm})$ [12,41], and digital photography $(0.8 \mathrm{~mm})$ [13]. Furthermore, the kappa statistics showed only poor to fair observer concordance when detecting pupils over $6 \mathrm{~mm}$ with the SLBM. These results suggest therefore, that although 
both pupillometry techniques tested appear to be repeatable, the measurements should be performed by the same experienced examiner, because there is a rather high interobserver variability. Actually, both the SLBM and the CIP show relevant inaccuracies caused by examiner bias. One potential source of observer error could be attributed to the accuracy of the reticule of the CIP for measuring the pupil diameter [8]. This device measures pupils to 0.5_mm increments, thus the measurements were estimated to the nearest half millimeter. Therefore, this subjective interpretation could induce examiner digit preference bias. Beyond that, the distance at which the CIP is positioned relative to the eye may vary $[8,14]$. On the other hand, a potential source of examiner error in the slit-lamp method may be the tendency to focus the beam of blue light slightly more anteriorly or posteriorly with respect to the iris plane.

Slit-lamp pupillometry was moderately sensitive and quite specific in identifying pupil diameters over $6 \mathrm{~mm}$ (table 7). Using both, the first measurement and the mean of the three measurements, we found AUCs in the range of $0.83-0.88$, suggesting that the SLBM was a good, but not excellent, discriminator between pupils dilating more than 6 $\mathrm{mm}$ and those with diameters not exceeding $6 \mathrm{~mm}$. In addition, we found little difference between the ROC curves obtained using the first measurement and mean of the three measurements. Interestingly, we found the best trade off between sensitivity and specificity for cutoff points between 5.4 and $5.5 \mathrm{~mm}$ of pupil diameter on half of the curves, which represent values with scarce clinical utility $[9,10,42]$. We selected a $6 \mathrm{~mm}$ pupil diameter cut off because it is typically the maximum optic diameter of the phakic and pseudophakic IOLs $[5,31]$, and as a result of the data reported by several authors who used previously Colvard [10,12,16,17,21,24,33,34] under LM conditions (range: 0.05 to 1 lux) in subjects ranged from 25.7 to 38.8 years old (mean age: 34.47 years, our subjects mean age: 34.5 years) obtained a mean pupil size of $5.98+/-0.19 \mathrm{~mm}$. 
The association between pupil size, optic quality, and patient satisfaction is multifactorial $[5,31]$ and it is not known yet what exact relationship between pupil size and optical zone diameter should be to prevent vision disturbance $[42,43]$. However, wavefront

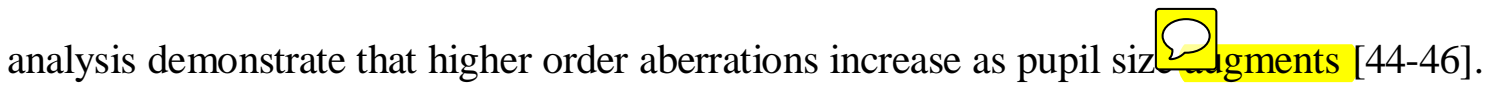
Some visual disturbances following anterior segment surgery, specially at night, have been linked to a disparity between the pupil size under LM illumination and the effective excimer laser optical zone $[1,3,43,47]$ or the IOL optic [5]. Therefore, the result of an erroneous underestimation of pupil diameter, such as the ones we have observed in this study, may not only affect the planning of the ablation zone or the choice of the optical features of the monofocal or multifocal IOL to be inserted, but also may risk inducing night visual disturbances or impair light distribution for the far and near focus, respectively $[3,7,42-47]$.

This study has several limitations. First, SLBM was compared to CIP, whose main disadvantage is its dependence on examiner subjective estimation. However, this shortcoming can be overcome by an experienced examiner [48], as the ones who performed the current study. In fact, the results of our investigation and previous ones [17], indicate that CIP produce repeatable measurements. Second, there may also be a limitation in comparing the two techniques since the increments of the CIP were 0.5 $\mathrm{mm}$ and the SLBM was $0.1 \mathrm{~mm}$. However, the maximum measurement difference between both devices should be only of $0.2 \mathrm{~mm}$, which would be the case for instance of a pupil measuring $6.7 \mathrm{~mm}$ by SLBM and being rounded to $6.5 \mathrm{~mm}$ by CIP, or a pupil measuring $6.8 \mathrm{~mm}$ by SLBM and being rounded to $7 \mathrm{~mm}$ by CIP. Furthermore, random distribution of pupil size, like in this study, leads to cancellation of round up and round down readings across measurements and eyes. Third, another limitation might be the infrared pupillometer used as a comparison device to validate the SLBM; several 
studies have demonstrated that digital infrared pupillometry might yield larger pupil diameter than $C$ and has got better repeatability [12,22], however this discrepancy has been described especially when the pupil diameter was measured under scotopic illuminance conditions $(<0.05$ lux $)$, which are reached solely in an experimental setting, but not during the patient mesopic daily activity [10,26]. Furthermore, another commercial handheld infrared pupillometer could have been used (Neuroptics, NeurOptics, Inc) in this study, which also has been reported to provide similar interobserver variability and larger pupil diameter than CIP [17]. However, CIP is still the most used device as a pupil gauge instrument (Duffey RJ and Leaming DV. U.S. Trends in refractive surgery: the 2009 ISRS survey. Presented at: AAO Annual Meeting, October 24, 2009; San Francisco). Last, this study did not address specifically the pupil size measurement after excimer laser refractive surgery. Nevertheless, Spadea et al [49]. could not find significant differences in pupil size measurements before and after a broad range of myopic and hyperopic laser vision correction procedures.

In conclusion, we found that measuring pupil size under LM illumination at the slit-lamp by using dim cobalt-blue-filtered light is not reliable enough to be used routinely in clinical practice. We acknowledge that although it is repeatable, easy to perform, not time consuming, and it is not necessary to acquire specific instrumentation, this dim cobalt-blue-light slit-lamp pupillometry method tends to noticeably underestimate pupil size, yielding therefore low sensitivities in detecting larger pupils, shows poor interobserver repeatability because of examiner bias, and for some observers its diagnostic characteristics make it more appropriate for discriminating pupil diameters at a cutoff value well under $6 \mathrm{~mm}$, which might not be clinically useful $[9,10,42]$. The American Society of Cataract and Refractive Surgery, American Academy of Ophthalmology, Federal Trade Commission, Food and Drug 
Administration, and Ophthalmic Mutual Insurance Company have issued statements regarding pupil size in refractive surgery. Whereas dim-light pupil size alone may not predict who will experience night vision disturbances after keratorefractive surgery, particularly after wavefront-guided LASIK [50], the functional optical zone-pupil size mismatch, termed "negative clearance" [51], may be more closely related. Moreover, in the correction of higher ametropias, the effective optical zone tends to be smaller than the laser ablation nominal optical zone [52], and with phakic IOLs, the pupil-optical zone disparity is also greater [53], which favors the results of several studies reporting the degree of ametropia as a risk factor for night vision complaints [53,54]. In multifocal pseudo-phakic IOL implantation, pupil size determines the distribution of the near and far focus in many lens designs $[7,55]$, and is one of the three major risk factors for patient dissatisfaction [56]. Therefore, accurate pupil measurement is important for both, planning surgery and gauging the risk of side effects from surgery. We should bear in mind that many patients are going to live with decisions based on such pupil measurements for the rest of their lives. Accordingly, the results of this study indicate that a surgical plan founded on the slitlamp-based cobalt blue light pupillometry should not be developed. 


\section{ACKNOWLEDGEMENTS}

Supported in part by RETICS RD07/0062 (Oftalmología), and the Spanish Ministry of Education and Science through the research project FIS2005-05020-C03-03. 


\section{REFERENCES}

1. Nixon WS (1997) Pupil size in refractive surgery. J Cataract Refract Surg 23:14351436.

2. Colvard M (1999) Preoperative measurement of scotopic pupil dilation using an office pupillometer. J Cataract Refract Surg 24:1594-1597.

3. Fan-Paul NI, Li J, Miller JS, Florakis GJ (2002) Night vision disturbances after corneal refractive surgery. Surv Ophthalmol 47:533-546.

4. Helgesen A, Hjortdal J, Ehlers N (2004) Pupil size and night vision disturbances after LASIK for myopia. Acta Ophthalmol Scand 82:454-460.

5. Alió JL, de la Hoz F, Pérez-Santonja JJ, Ruiz-Moreno JM, Quesada JA (1999) Phakic anterior chamber lenses for the correction of myopia. A 7-year cumulative analysis of complications in 263 cases. Ophthalmology 106:458-466.

6. Pieh S, Lackner B, Hanselmayer G, Zöhrer R, Sticker M, Weghaupt H, Fercher A, Skorpik C (2001) Halo size under distance and near conditions in refractive multifocal intraocular lenses. Br J Ophthalmol 85:816-821.

7. Alfonso JF, Fernández-Vega L, Baamonde MB, Montés-Micó R (2007) Correlation of pupil size with visual acuity and contrast sensitivity after implantation of an apodized diffractive intraocular lens. J Cataract Refract Surg 33:430-438.

8. Pop M, Payette Y, Santoriello E (2002) Comparison of the pupil card and pupillometer in measuring pupil size. J Cataract Refract Surg 28:283-288.

9. Wachler BS, Krueger RR (1999) Agreement and repeatability of infrared pupillometry and the comparison method. Ophthalmology 106:319-323. 
10. Schnitzler EM, Baumeister M, Kohnen T (2000) Scotopic measurement of normal pupils: Colvard versus Video Vision Analyzer infrared pupillometer. J Cataract Refract Surg 26:859-866.

11. Rosen ES, Gore CL, Taylor D, Chitkara D, Howes F, Kowalewski E (2002) Use of a digital infrared pupillometer to assess patient suitability for refractive surgery. $\mathrm{J}$ Cataract Refract Surg 28:1433-1438.

12. Kohnen T, Terzi E, Buhren J, Kohnen EM (2003) Comparison of a digital and a handheld infrared pupillometer for determining scotopic pupil diameter. J Cataract Refract Surg 29:112-117.

13. Michel AW, Kronberg BP, Narváez J, Zimmerman G (2006) Comparison of 2 multiple-measurement infrared pupillometers to determine scotopic pupil diameter. J Cataract Refract Surg 32:1926-1931.

14. Twa MD, Bailey MD, Hayes J, Bullimore M (2004) Estimation of pupil size by digital photography. J Cataract Refract Surg 30:381-389.

15. Yang H, Lee M, Kim JB, Ahn J (2006) Burst-shot infrared digital photography to determine scotopic pupil diameter. J Cataract Refract Surg 32:2113-2117.

16. Ho LY, Harvey TM, Scherer J, Balasubramaniam M, Dhaliwal DK, Mah FS (2009) Comparison of Rosenbaum Pupillometry Card Using Red and Blue Light to Colvard and Iowa Pupillometers. J Refract Surg 2:1-7.

17. Schallenberg M, Bangre V, Steuhl KP, Kremmer S, Selbach JM (2010) Comparison of the Colvard, Procyon, and Neuroptics pupillometers for measuring pupil diameter under low ambient illumination. J Refract Surg 26:134-143.

18. Bradley JC, Bentley KC, Mughal AI, Brown SM (2010) Clinical performance of a handheld digital infrared monocular pupillometer for measurement of the darkadapted pupil diameter. J Cataract Refract Surg 36:277-281. 
19. Starck T, Liu Y, Prewett AL, Curup LG (2002) Comparison of scotopic pupil measurement with slitlamp-based cobalt blue light and infrared video-based system. J Cataract Refract Surg 28:1952-1956.

20. Chaglasian EL, Akbar S, Probst LE (2006) Pupil measurement using the Colvard pupillometer and a standard pupil card with a cobalt blue filter penlight. J Cataract Refract Surg 32:255-260.

21. Hsieh YT, Hu FR (2007) The correlation of pupil size measured by Colvard pupillometer and Orbscan II. J Refract Surg 23:789-795.

22. Bootsma S, Tahzib N, Eggink F, de Brabander J, Nuijts R (2007) Comparison of two pupillometers in determining pupil size for refractive surgery. Acta Ophthalmol Scand 85:324-328.

23. Rocha KM, Soriano ES, Chamon W, Chalita MR, Nosé W (2007) Spherical aberration and depth of focus in eyes implanted with aspheric and spherical intraocular lenses: a prospective randomized study. Ophthalmology 114:2050-2054.

24. McDonnell C, Rolincova M, Venter J (2006) Comparison of measurement of pupil sizes among the colvard pupillometer, procyon pupillometer, and NIDEK OPDscan. J Refract Surg 22:1027-1030.

25. Yoon MK, Schmidt G, Lietman T, McLeod SD (2007) Inter- and intraobserver reliability of pupil diameter measurement during 24 hours using the Colvard pupillometer. J Refract Surg 23:266-271.

26. Colvard M (1998) Preoperative measurement of scotopic pupil dilation using an office pupillometer. J Cataract Refract Surg 24:1594-1597.

27. Ray WA, O'Day DM (1985) Statistical analysis of multi-eye data in ophthalmic research. Invest Ophthalmol Vis Sci 26:1186-1188. 
28. Bland JM, Altman DG (1986) Statistical methods for assessing agreement between two methods of clinical measurement. Lancet 1:307-310.

29. Bland JM, Altman DG (1996) Measurement error and correlation coefficients. BMJ;313:41-42.

30. Margo, CE, Harman LE, Mulla ZD (2002) The reliability of clinical methods in ophthalmology. Surv Ophthalmol 47:375-386.

31. Jin Y, Zabriskie N, Olson RJ (2009) Dysphotopsia outcomes analysis of two truncated acrylic 6.0-mm intraocular optic lenses. Ophthalmologica 223:47-51.

32. Fleiss J (1981) Statistical methods for rates and proportions. John Wiley \& Sons Inc. New York, NY. pp 212-236.

33. Kohnen T, Terzi E, Kasper T, Kohnen EM, Bühren J (2004) Correlation of infrared pupillometers and CCD-camera imaging from aberrometry and videokeratography for determining scotopic pupil size. J Cataract Refract Surg 30:2116-2123.

34. Cheng AC, Lam DS (2004) Comparison of the Colvard pupillometer and the Zywave for measuring scotopic pupil diameter. J Refract Surg 20:248-252.

35. Griner PF, Mayewski RJ, Mushlin AI, Greenland P (1981) Selection and interpretation of diagnostic tests and procedures. Principles and applications. Ann Intern Med 94:557-592.

36. Metz CE (1978) Basic principles of ROC analysis. Semin Nucl Med 8:283-298.

37. Bouma H (1962) Size of the static pupil as a function of wavelength and luminosity of the light incident on the human eye. Nature;193:690-691.

38. Adrian W (2003) Spectral sensitivity of the pupillary system. Clin Exp Optom $86: 235-238$.

39. Kardon R, Anderson SC, Damarjian TG, Grace EM, Stone E, Kawasaki A (2009) Chromatic pupil responses: preferential activation of the melanopsin-mediated 
versus outer photoreceptor-mediated pupil light reflex. Ophthalmology 116:15641573.

40. Howarth PA, Heron G, Whittaker L (2000) The measurement of pupil cycling time. Graefe's Arch Clin Exp Ophthalmol 238:826-832.

41. Robl C, Sliesoraityte I, Hillenkamp J, Prahs P, Lohmann CP, Helbig H, Herrmann WA (2009) Repeated pupil size measurements in refractive surgery candidates. J Cataract Refract Surg 35:2099-2102

42. Schallhorn SC, Kaupp SE, Tanzer DJ, Tidwell J, Laurent J, Bourque LB (2003) Pupil size and quality of vision after LASIK. Ophthalmology 110;1606-1614.

43. Roberts CW, Koester CJ (1993) Optical zone diameters for photorefractive corneal surgery. Invest Ophthalmol Vis Sci 34:2275-2281.

44. Kohnen T, Bühren J, Kühne C, Mirshahi A (2004) Wavefront-guided LASIK with the Zyoptix 3.1 system for the correction of myopia and compound myopic astigmatism with 1-year follow-up: clinical outcome and change in higher order aberrations. Ophthalmology 111:2175-2185.

45. Oshika T, Klyce SD, Applegate RA, Howland HC, El Danasoury MA (1999) Comparison of corneal wavefront aberrations after photorefractive keratectomy and laser in situ keratomileusis. Am J Ophthalmol 127:1-7.

46. Martínez CE, Applegate RA, Klyce SD, McDonald MB, Medina JP, Howland HC (1998). Effect of pupillary dilation on corneal optical aberrations after photorefractive keratectomy. Arch Ophthalmol 116:1053-1062.

47. Maguire LJ (1994) Keratorefractive surgery, success, and the public health. Am J Ophthalmol 117:394-398. 
48. Bradley JC, Anderson JE, Xu KT, Brown SM (2005) Comparison of Colvard pupillometer and infrared digital photography for measurement of the dark-adapted pupil diameter. J Cataract Refract Surg 31:2129-2132.

49. Spadea L, Giammaria D, Ferrante R, Balestrazzi E (2005) Pre-excimer laser and post-excimer laser refractive surgery measurements of scotopic pupil diameter using 2 pupillometers. Ophthalmology 112:1003-1008.

50. Chan A, Manche EE (2011) Effect of preoperative pupil size on quality of vision after wavefront-guided LASIK. Ophthalmology 118:736-741.

51. Bühren J, Kühne C, Kohnen T (2005) Influence of pupil and optical zone diameter on higher-order aberrations after wavefront-guided myopic LASIK. J Cataract Refract Surg 31:2272-2280.

52. Holladay JT, Janes JA (2002) Topographic changes in corneal asphericity and effective optical zone after laser in situ keratomileusis. J Cataract Refract Surg 28:942-947.

53. Tahzib NG, Bootsma SJ, Eggink FA, Nuijts RM (2006) Functional outcome and patient satisfaction after Artisan phakic intraocular lens implantation for the correction of myopia. Am J Ophthalmol 142:31-39.

54. Pop M, Payette Y (2004) Risk factors for night vision complaints after LASIK for myopia. Ophthalmology 111:3-10.

55. Alió JL, Elkady B, Ortiz D, Bernabeu G (2008) Clinical outcomes and intraocular optical quality of a diffractive multifocal intraocular lens with asymmetrical light distribution. J Cataract Refract Surg 34:942-948.

56. de Vries NE, Webers CA, Touwslager WR, Bauer NJ, de Brabander J, Berendschot TT, Nuijts RM (2011) Dissatisfaction after implantation of multifocal intraocular lenses. J Cataract Refract Surg 37:859-865. 


\section{ACKNOWLEDGEMENTS}

Supported in part by RETICS RD07/0062 (Oftalmología), and the Spanish Ministry of Education and Science through the research project FIS2005-05020-C03-03. 


\section{FIGURE LEGENDS}

Figure 1. Diagram of the study design.

Figure 2. Agreement between slit-lamp biomicroscope and infrared pupillometry

(Colvard). (a) First measurement for examiner 1. (b) First measurement for examiner 2.

(c) Mean of three measurements for examiner 1. (d) Mean of three measurements for examiner 2.

Figure 3. Interobserver repeatability. (a) First measurement with slit-lamp biomicroscope. (b) First measurement with Colvard. (c) Mean of three measurements with slit-lamp biomicroscope. (d) Mean of three measurements with Colvard.

Figure 4. ROC curves for the detection of mesopic pupil sizes larger than $6.0 \mathrm{~mm}$. (a) First measurement for examiner 1. (b) First measurement for examiner 2. (c) Mean of three measurements for examiner 1. (d) Mean of three measurements for examiner 2. 


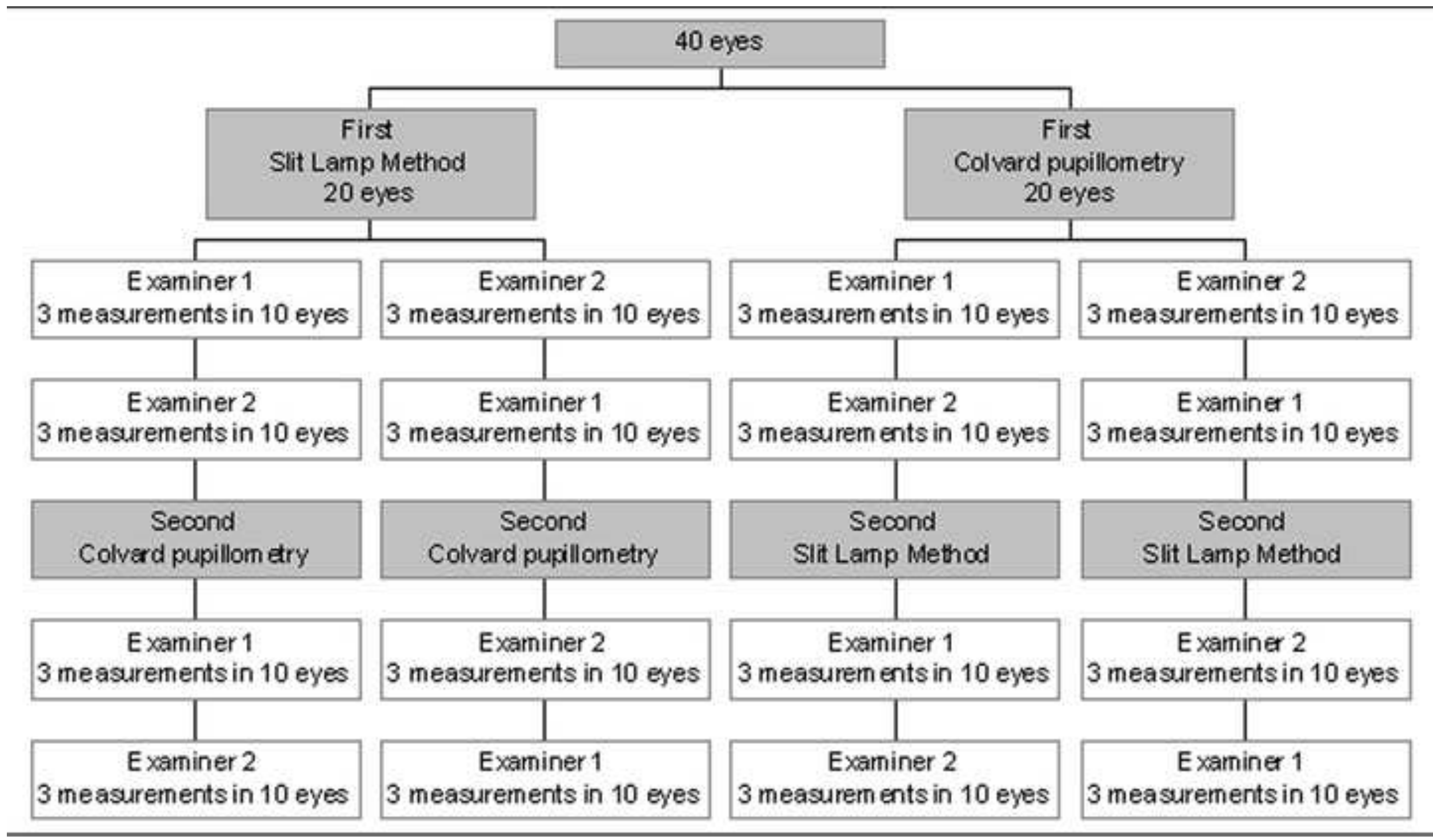




\section{EAMNER 1}

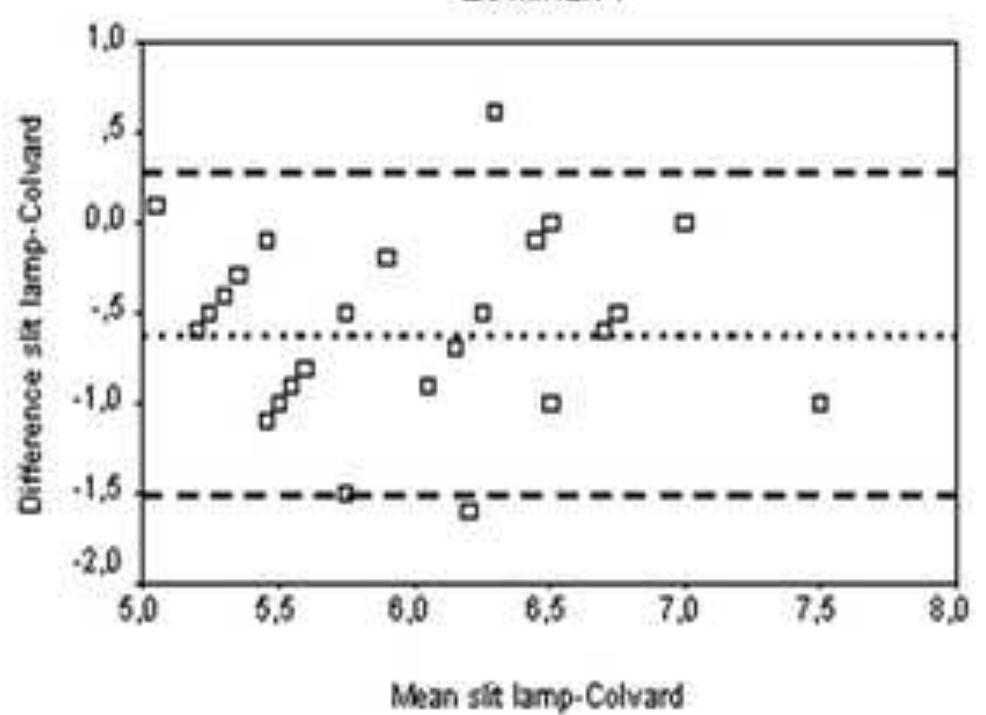

A

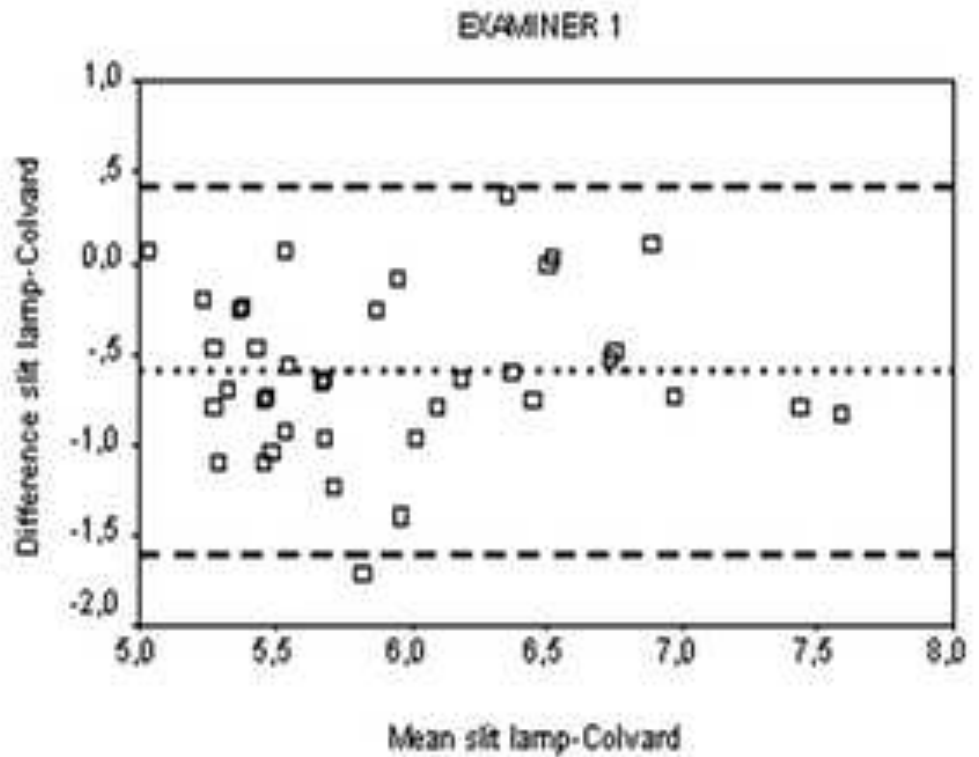

C
DXAMNER 2

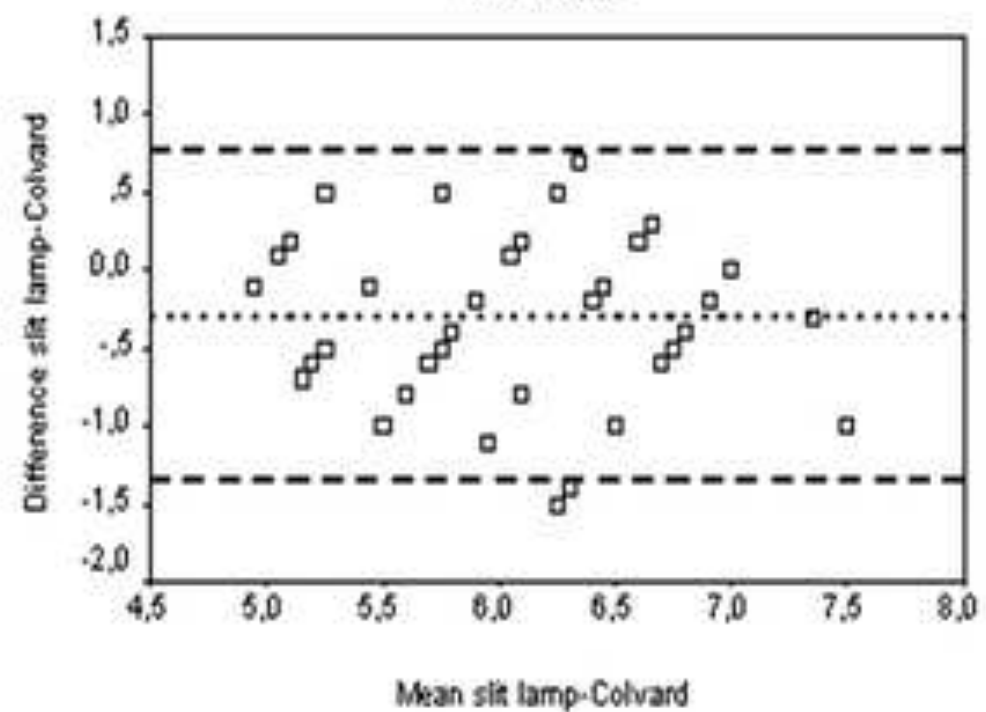

B

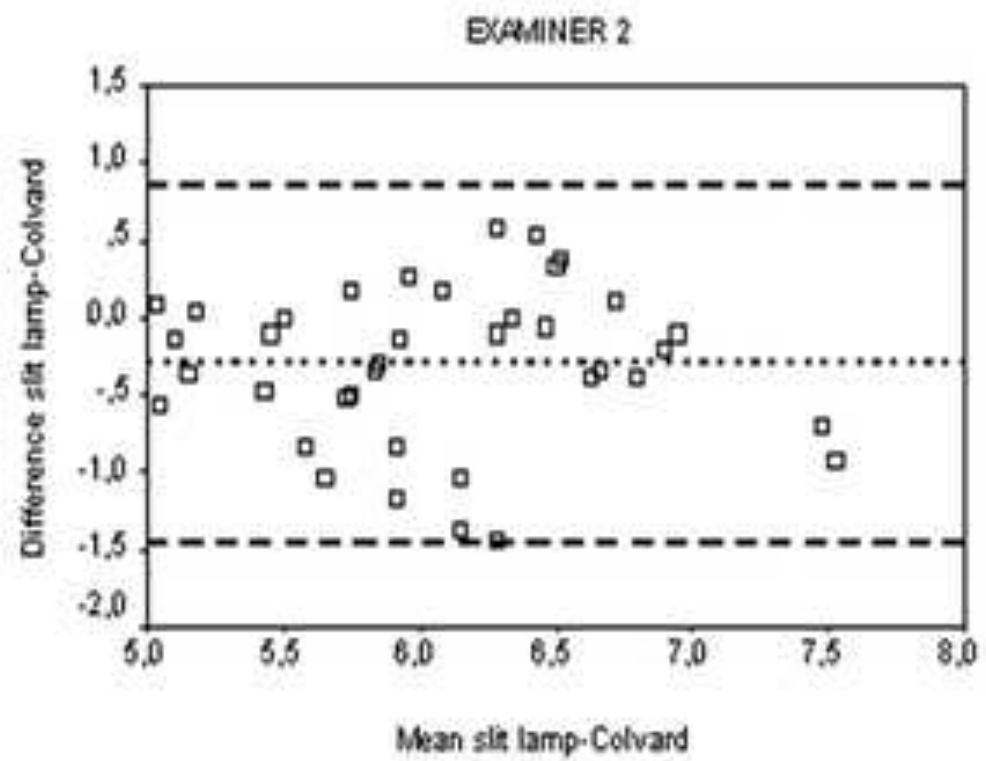

D 
Common.Links.ClickHereToDownloadHighResolutionImage

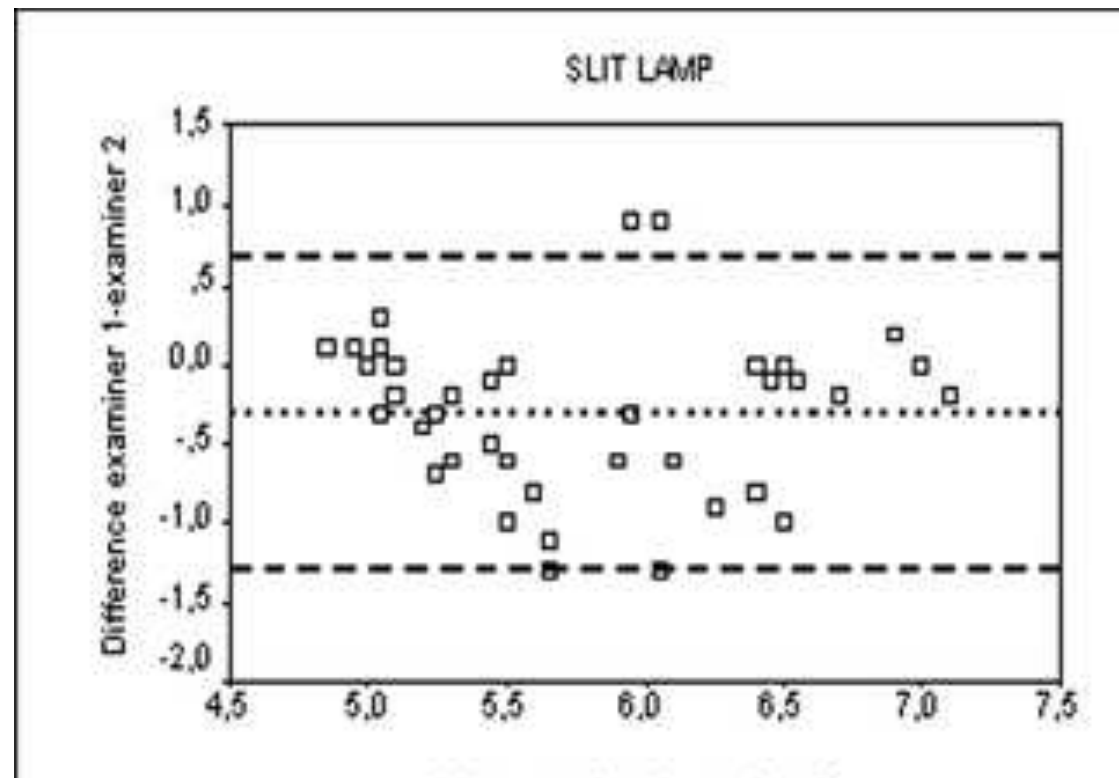

Mean examiner 1-examiner 2

A

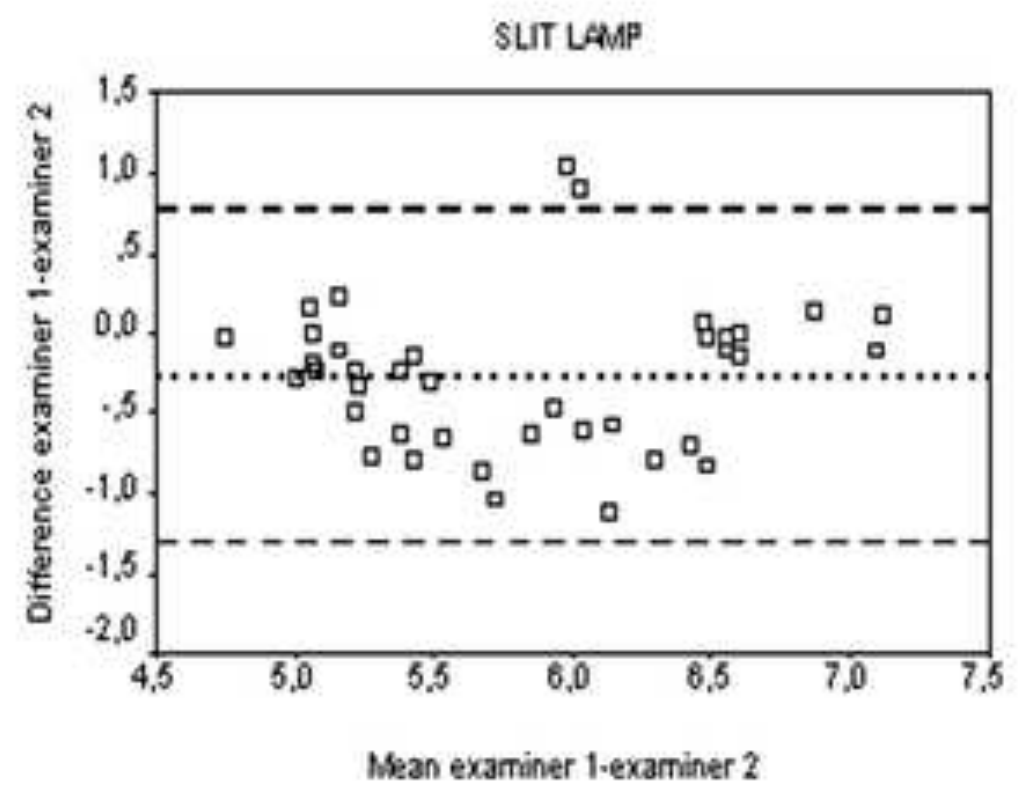

C

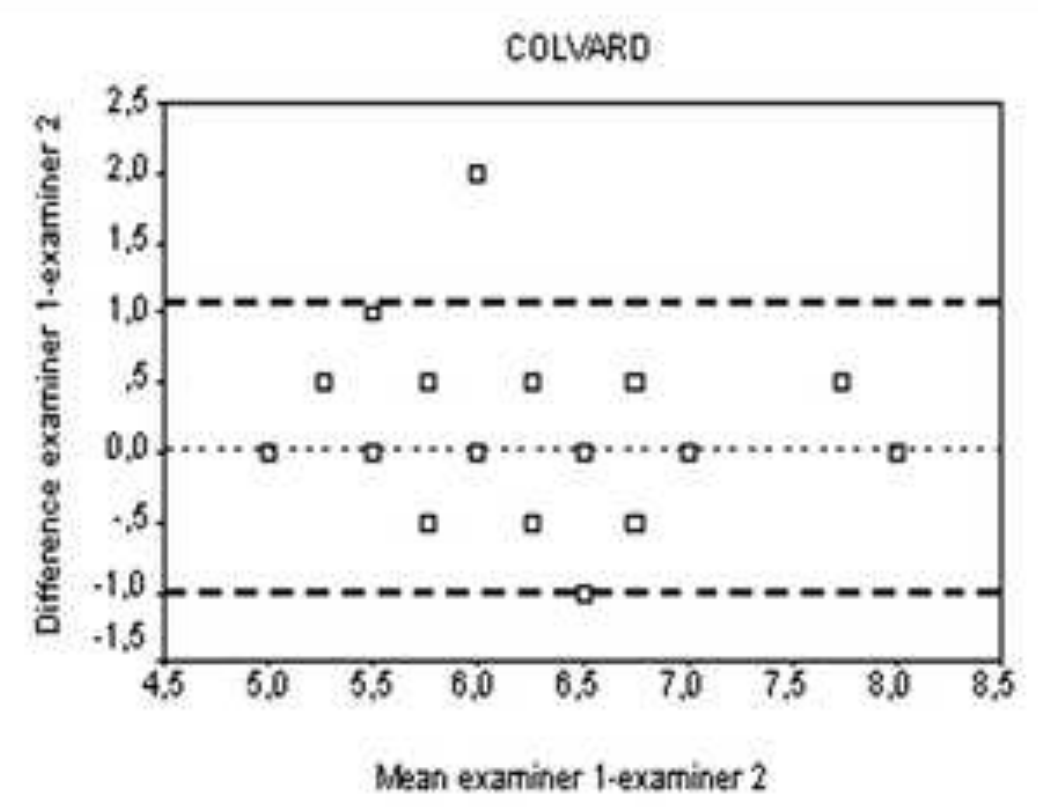

B

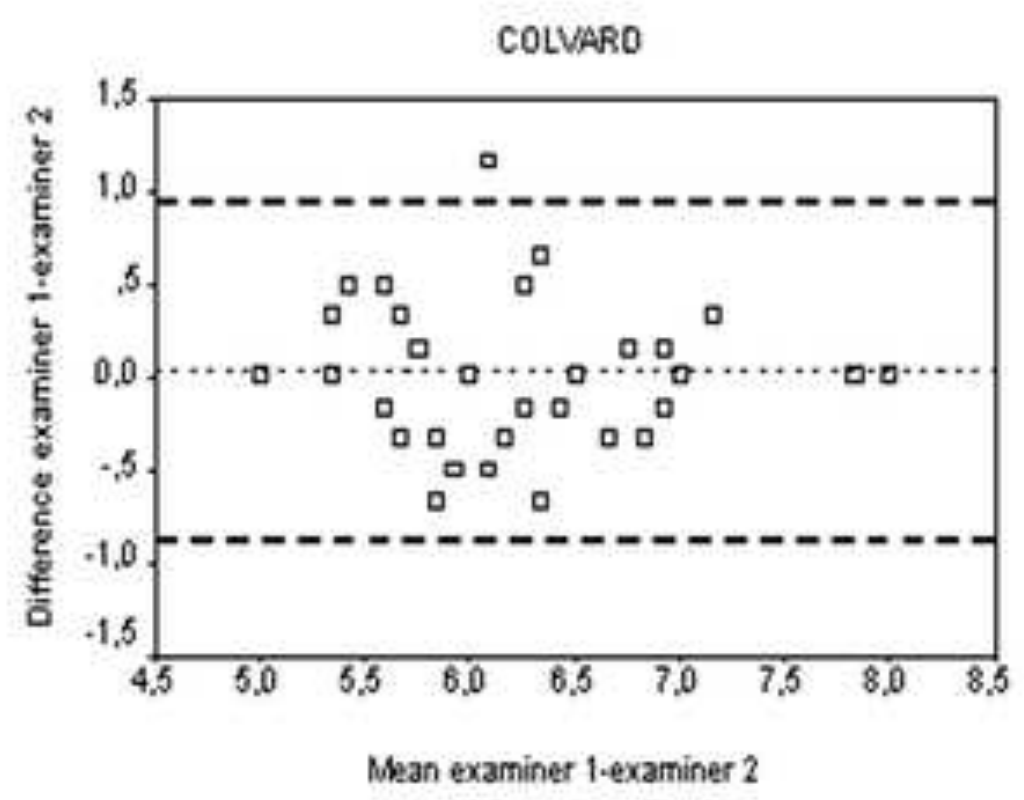

D 


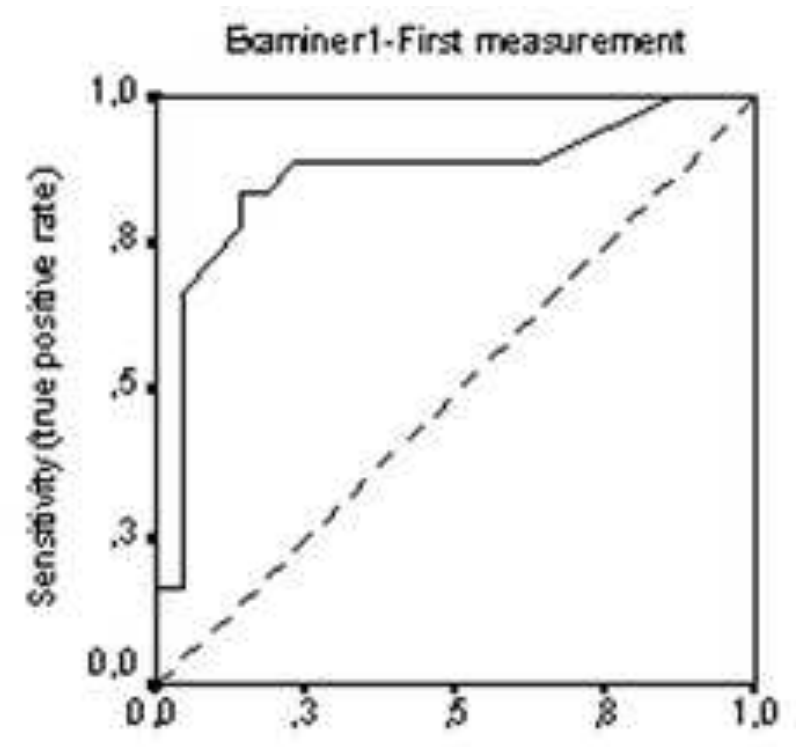

1. Specificity (talse positive rate)

A

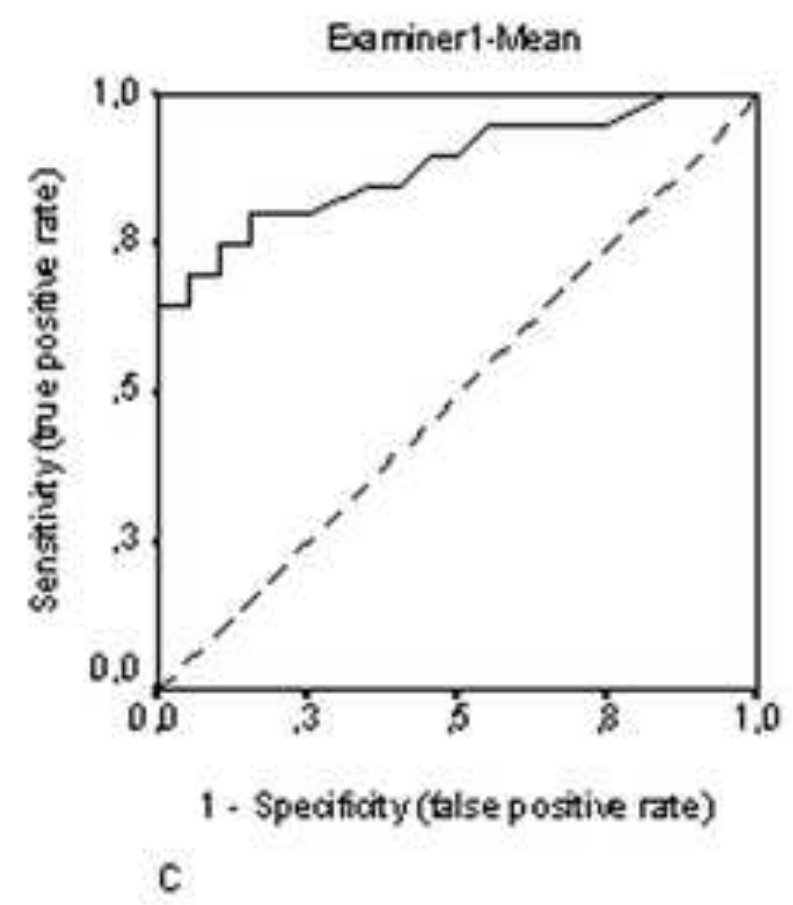

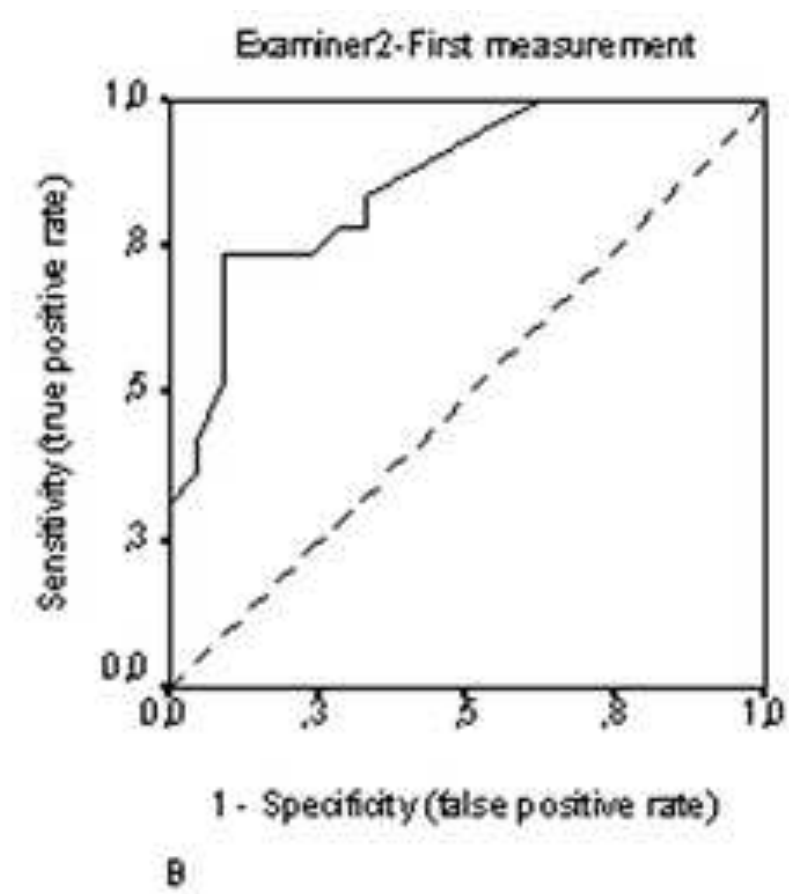

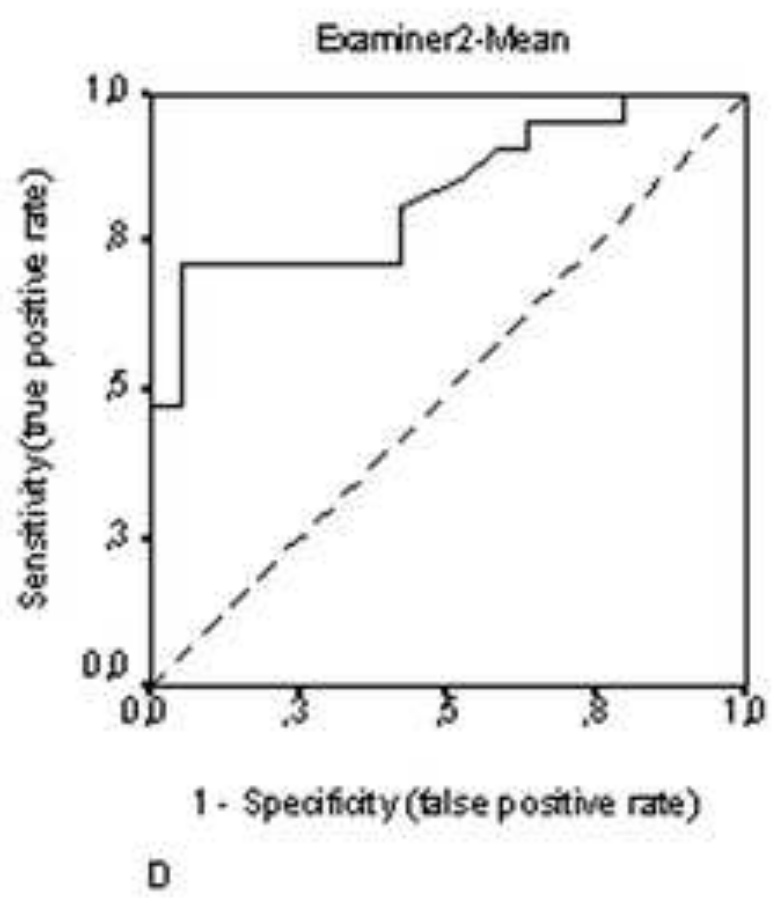


Table 1. Mean mesopic pupil measurements.

\begin{tabular}{lcccc}
\cline { 2 - 4 } & $\begin{array}{c}\text { Slit-lamp } \\
(\text { mean } \pm \mathbf{S D})\end{array}$ & $\begin{array}{c}\text { Colvard } \\
(\text { mean } \pm \mathbf{S D})\end{array}$ & P-value & 95\% Cl \\
\hline Overall $(\mathrm{mm})$ & $5.81 \pm 0.70$ & $6.26 \pm 0.68$ & 0.01 & -0.52 to -0.38 \\
Examiner 1 $(\mathrm{mm})$ & $5.67 \pm 0.70$ & $6.27 \pm 0.68$ & 0.01 & -0.74 to -0.46 \\
Examiner 2 $(\mathrm{mm})$ & $5.95 \pm 0.67$ & $6.25 \pm 0.69$ & 0.02 & -0.46 to -0.14 \\
P-value & 0.02 & 0.81 & & \\
95\% Cl $(\mathrm{mm})$ & -0.42 to -0.13 & -0.10 to 0.14 & & \\
\hline
\end{tabular}

SD. Standard deviation. CI. Confidence interval. 
Table 2. The 95\% limits of agreement (LoA) between slit-lamp biomicroscopy-based method and Colvard pupillometry for the first measurement and for the mean of the three measurements.

\begin{tabular}{lllll}
\hline Mean difference & $95 \% \mathrm{Cl}$ & P-value & $95 \%$ LoA & Width of \\
$\left(\mathrm{CIP}^{\star}-\mathrm{SLBM}^{\star \star}\right)$ & & & & the range
\end{tabular}

\begin{tabular}{llllll}
\hline First measurement & & & & & \\
Examiner $1(\mathrm{~mm})$ & -0.63 & -0.77 to -0.48 & 0.01 & -1.50 to 0.27 & 1.79 \\
Examiner $2(\mathrm{~mm})$ & -0.30 & -0.47 to -0.12 & 0.02 & -1.34 to 0.75 & 2.09 \\
\hline Mean of 3 Measurements & & & & & \\
Examiner $\mathbf{1}(\mathrm{mm})$ & -0.60 & -0.74 to -0.46 & 0.01 & -1.61 to 0.42 & 2.03 \\
Examiner $2(\mathrm{~mm})$ & -0.30 & -0.46 to -0.14 & 0.02 & -1.45 to 0.85 & 2.30 \\
\hline
\end{tabular}

*CIP: Colvard infrared pupillometry. **. SLBM: slit-lamp biomicroscopy-based method. LoA: Limits of agreement. 
Table 3. The intraobserver within-subject standard deviation $\left(S_{\mathrm{w}}\right)$, the within-subject coefficient of variation $\left(\mathrm{CV}_{\mathrm{w}}\right)$, and the Intraclass Correlation Coefficient (ICC) for SLBM and CIP.

\begin{tabular}{|c|c|c|c|c|}
\hline & & $\mathrm{S}_{\mathrm{w}}(95 \% \mathrm{Cl})$ & $\mathrm{CV}_{\mathrm{w}}(\%)$ & ICC (95\% Cl) \\
\hline \multirow{2}{*}{ Examiner 1} & SLBM $^{*}$ & $\begin{array}{c}0.122 \\
(0.095 \text { to } 0.149)\end{array}$ & 2.15 & $\begin{array}{c}0.970 \\
\text { (0.951 to } 0.983)\end{array}$ \\
\hline & $\mathrm{CIP}^{\star *}$ & $\begin{array}{c}0.137 \\
(0.107 \text { to } 0.167)\end{array}$ & 2.31 & $\begin{array}{c}0.959 \\
(0.932 \text { to } 0.977)\end{array}$ \\
\hline \multirow{2}{*}{ Examiner 2} & SLBM $^{*}$ & $\begin{array}{c}0.194 \\
(0.151 \text { to } 0.236)\end{array}$ & 3.09 & $\begin{array}{c}0.920 \\
(0.870 \text { to } 0.954)\end{array}$ \\
\hline & $\mathrm{CIP}^{\star *}$ & $\begin{array}{c}0.219 \\
(0.171 \text { to } 0.267)\end{array}$ & 3.50 & $\begin{array}{c}0.903 \\
(0.844 \text { to } 0.944)\end{array}$ \\
\hline
\end{tabular}

*SLBM: slit-lamp biomicroscopy-based method. **CIP: Colvard infrared pupillometry. 
Table 4. The 95\% LoA between two examiners by method, for the first measurement and for the mean of the three measurements.

\begin{tabular}{|c|c|c|c|c|c|}
\hline & $\begin{array}{c}\text { Mean } \\
\text { difference }\end{array}$ & $95 \% \mathrm{Cl}$ & P-value & $95 \%$ LoA $^{\star \star *}$ & $\begin{array}{l}\text { Width of } \\
\text { the range }\end{array}$ \\
\hline \multicolumn{6}{|c|}{ First measurement } \\
\hline $\operatorname{SLBM}^{\star}(\mathrm{mm})$ & -0.31 & -0.47 to -0.14 & 0.01 & -1.29 to 0.68 & 1.97 \\
\hline $\mathrm{CIP}^{\star *}(\mathrm{~mm})$ & 0.03 & -0.15 to 0.20 & 0.89 & -1.02 to 1.07 & 2.09 \\
\hline \multicolumn{6}{|c|}{ Mean of 3 measurements } \\
\hline $\operatorname{SLBM}^{\star}(\mathrm{mm})$ & -0.30 & -0.42 to -0.13 & 0.02 & -1.32 to 0.77 & 2.09 \\
\hline $\operatorname{CIP}^{\star \star}(\mathrm{mm})$ & 0.02 & -0.10 to 0.14 & 0.85 & -0.89 to 0.93 & 1.82 \\
\hline
\end{tabular}

*SLBM: slit-lamp biomicroscopy-based method. **CIP: Colvard infrared pupillometry. CI: Confidence interval. ***LoA: Limits of agreement. 
Table 5. Coefficients of interobserver repeatability (in millimeters) for slit-lamp biomicroscope and Colvard pupillometry

\begin{tabular}{lcc}
\cline { 2 - 3 } & Slit-lamp & Colvard \\
\hline First measurement & 0.99 & 1.04 \\
Mean of 3 measurements & 1.05 & 0.91 \\
\hline
\end{tabular}


Table 6. Kappa statistic: interobserver reliability in detecting pupils over $6 \mathrm{~mm}$.

\begin{tabular}{lcc}
\cline { 2 - 3 } & Kappa & $95 \% \mathrm{Cl}$ \\
\hline First measurement & 0.39 & 0.09 to 0.68 \\
Slit-lamp & 0.45 & 0.17 to 0.72 \\
Colvard & & \\
\hline Mean of 3 measurements & 0.49 & 0.22 to 0.76 \\
Slit-lamp & 0.45 & 0.17 to 0.73 \\
Colvard & & \\
\hline
\end{tabular}

CI: Confidence inteval. 
Table 7. Sensitivity, specificity and efficiency of the slit-lamp pupillometry for detection of pupil sizes larger than $6.0 \mathrm{~mm}$ for the first measurement and for the mean of the three measurements.

\begin{tabular}{lccc}
\cline { 3 - 4 } & Sensitivity & Specificity & Efficiency \\
\hline First measurement & $55.56 \%$ & $95.45 \%$ & $77.5 \%$ \\
Examiner 1 & $73.68 \%$ & $76.19 \%$ & $75 \%$ \\
Examiner 2 & & & \\
\hline Mean of the three measurements & $65 \%$ & $100 \%$ & $82.5 \%$ \\
Examiner 1 & $71.43 \%$ & $78.95 \%$ & $75 \%$ \\
Examiner 2 & & & \\
\hline
\end{tabular}


Table 8. Area under ROC curves and the corresponding standard errors (SE).

\begin{tabular}{lccc|}
\cline { 2 - 4 } & AUC & SE & $95 \% \mathrm{Cl}$ \\
\hline Ex1-First & 0.865 & 0.065 & 0.738 to 0.992 \\
Ex2-First & 0.862 & 0.057 & 0.751 to 0.974 \\
Ex1-Mean & 0.883 & 0.055 & 0.775 to 0.990 \\
Ex2-Mean & 0.831 & 0.065 & 0.704 to 0.958 \\
\hline
\end{tabular}

CI: Confidence interval. 